\title{
Numerical and Experimental Investigation on the Aerodynamic performance of roller Airfoil
}

\author{
M. Senthil Kumar ${ }^{1}$, R. Vijayanandh ${ }^{1}$, N. Kaviarasan ${ }^{1}$, R. Dinesh Kumar ${ }^{1}$, I. Adrin Issai Arasu ${ }^{2}$ and R. Kanmani- \\ raja $^{3}$ \\ ${ }^{I}$ Department of Aeronautical Engineering, Kumaraguru College of Technology, Coimbatore, Tamil Nadu, India \\ ${ }^{2}$ Lowa State University, United States \\ ${ }^{3}$ Korea Aerospace University, Republic of Korea \\ *Corresponding author E-mail: senthilkumar.m.aeu@kct.ac.in
}

\begin{abstract}
Prevailing norm is a fixed wing in a conventional aircraft, but the prospect appears bright for developing wings that could yield better aerodynamic properties with a change in the form and shape, this may have a wider application in future aviation. The main objective of this paper is to probe such a morphing technology in wings to improve their aerodynamic performance while operating at various cruise conditions. The airfoil is equipped with a rolling mechanism on its upper surface, operated by custom- designed controllers. This roller airfoil model will generate higher lift at low angles of attack and substantially increase flight performance, leading to the evolution of a create multiple-regime, aerodynamically efficient aircraft. This paper aims to compare the performance enhancement of roller airfoil over a conventional airfoil, by increasing the velocity at the upper surface of the airfoil to increase the lift to drag ratio using typical engineering analyses. The cambered airfoil chosen here is NACA 4412. Morphing concept brings about the improvement due to a reduction in lift-induced drag by promoting large laminar flow run on the upper surface of the wing.
\end{abstract}

Keywords: Aerodynamics; Airfoil; Boundary layer; Computational Fluid Dynamics; Roller.

\section{Introduction}

The conceptual design and analysis of the wings of an aircraft are one of the prime factors involved in airplane design, in which lift to drag ratio plays a vital role in the expression of wing's aerodynamic design quality. A high lift-to-drag ratio requires a considerably smaller thrust to propel the wings through the air at sufficient lift. The boundary layer effect is a prime factor has to be considered in order to design the effective aeroplane wing, in which the effects of shear force between the working fluid and solid wing are large in the boundary layer. When aeroplane wing has undergone high relative velocity, the thin boundary layer flows smoothly over the streamlined shape of the airfoil, in a laminar flow. As the boundary layer approaches the center of the wing, it tends to lose speed due to skin friction and becomes thicker and turbulent. Beyond the transition point, drag due to skin friction is relatively high [1]. Boundary Layer Control (BLC) is a method of control the behavior of fluid flow in boundary layers, which is due to the physics involvement that is drag may be reduced while achieving high lift. BLC on wing deals with a huge amount of innovative ways to control the boundary layer of air on its body, which reduces the parasite drag and improves performance, increases the usable angle of attack $(\alpha)$ and dramatically improves lift at slow speeds. The implementation of BLC on an aeroplane may provide the greatest high improved aerodynamic performance compared to aircraft without BLC system [2].

\section{Literature Review}

Research on cambered airfoils, relying heavily on the shape characteristics of existing aerofoils have been carried out by Michael R. Reid for the purpose of Micro Air Vehicles [3]. The evolution of future airfoil designs implementation and its study was the only targeted outcome of this research which was raised from the analysis of the effectiveness of thin/cambered/reflexed airfoil. Emerging configuration is a set of cambered aerofoils which were experimentally investigated by $\mathrm{Re}$ and Leavitt. The experiments were conducted in order to review the static performance of the airfoil by analyzing the various geometrical parameters effects and pressure ratios. Also, implementations of computational methods to the flow field around cambered aerofoils have focused on the fluid-solid interaction. In which the computed flow had an external acceleration of fluid over the airfoil regime in addition to that primary description existing at the prescribed flow condition have been successfully captured for the airfoil [4]. Independent calculations on similar aerofoils were reported for two-dimensional cases. The shear layer can change the flow structure near the upper surface in an airfoil, therefore, simultaneously solving the flow field to account for the strongly interactive nature thus becomes necessary [5]. In recent years, the need to investigate the turbulent structure of the flow over dynamic upper surface airfoil for various practical applications is increasingly being realized [6]. These kinds of literature provide the clear view of existing problems and solution techniques involved in the cambered aerofoils, also which has given the aerofoil with roller concept in order to increase the performance of the aerofoil [7]. 


\section{Experimental and Theoretical Analysis}

\subsection{Conceptual Design - Modelling Assumptions}

1. The coordinates of airfoil NACA4412 are undisturbed by the position of the roller, 2. There is no gap between the roller and the surface i.e. the airfoil is continuous in the presence of the roller, 3 . Effects due to air passing through the gap between the roller and the airfoil are neglected and 4. Roller and airfoil are the same material.

\subsection{Position of Roller}

Position the roller accurately on the airfoil will increase the flow velocity over the upper surface and thus decreases the pressure. To accurately locate the point of steep drop in pressure, NACA 4412 have been analyzed at different angles of attack. The roller position from wall pressure coefficients over airfoil are as following: Roller tip is 0.13 chord, Roller end is 0.25 chord, Roller thickness is 0.10 chord and Roller length is 0.11 chord.

\subsection{Experimental Testing}

Experiments are carried out at a velocity of $50 \mathrm{~m} / \mathrm{s}$ in a low-speed subsonic wind tunnel. Airflow in the tunnel is generated by an axial flow fan driven by a DC motor. With the help of thyristor system, it is possible to vary smoothly the speed of the motor and realize a velocity range of 5 to $50 \mathrm{~m} / \mathrm{s}$ in the test section. The test is carried out in the test section of dimension $400 \times 400 \mathrm{~mm}$. In this paper, a roller has been used at the upper surface and a rigid skin in the lower surface of the airfoil where the rigid skin is made up of aluminum and the roller is of rubber material. Rubber is chosen due to its high tensile strength and its ability to facilitate a smooth flow. The roller is attached rigidly from $14 \%$ to $25 \%$ of the chord behind the airfoil's leading edge, on the upper surface of the airfoil. The dimensions chosen for the airfoil are chord length of 15 $\mathrm{cm}$ and the span of $30 \mathrm{~cm}$. The roller is made to rotate at $50 \mathrm{rpm}$, with the help of a battery eliminator (OSWAL $750 \mathrm{~mA}$ at 12 volts). Co-efficient of Lift $\left(\mathrm{C}_{\mathrm{L}}\right)$ and Co-efficient of Drag $\left(\mathrm{C}_{\mathrm{D}}\right)$ are obtained using the following equations and thereby the results are listed in table 1 .

$\mathrm{L}=0.5 \rho \mathrm{AV}^{2} \mathrm{C}_{\mathrm{L}}$

$\mathrm{D}=0.5 \rho \mathrm{AV}^{2} \mathrm{C}_{\mathrm{D}}$

Table 1: Experimental results of $C_{L}$ and $C_{D}$

\begin{tabular}{|c|c|c|c|}
\hline \multirow{2}{*}{$\begin{array}{c}\text { Angle of Attack } \\
\text { [ Degree] }\end{array}$} & \multicolumn{3}{|c|}{ NACA 4412 Airfoil with roller } \\
\cline { 2 - 4 } & $\mathrm{C}_{\mathrm{L}}$ & $\mathrm{C}_{\mathrm{D}}$ & $\mathrm{C}_{\mathrm{L}} / \mathrm{C}_{\mathrm{D}}$ \\
\hline 0 & 0.4505 & 0.0435 & 10.3563 \\
\hline 3 & 0.7795 & 0.0581 & 13.4165 \\
\hline 6 & 1.1083 & 0.0713 & 15.5445 \\
\hline 9 & 1.4370 & 0.0836 & 17.1889 \\
\hline 12 & 1.7662 & 0.1009 & 17.5045 \\
\hline 15 & 2.0954 & 0.1209 & 17.3317 \\
\hline
\end{tabular}

\subsection{Theoretical Analysis}

Thin Airfoil Theory, provides a means to predict the angle of zero lift as $[8,9]$ :

$\alpha_{\mathrm{I}=0}=-\frac{1}{\pi} \int_{0}^{\pi} \frac{d z}{d x}\left(\cos \theta_{0}-1\right) d \theta_{0}$

In the above equation $\frac{d z}{d x}$ is same as $\frac{d y}{d x}$, so $\frac{\mathrm{dy}}{\mathrm{dx}}=\frac{\mathrm{dz}}{\mathrm{dx}}$ hence $\frac{\mathrm{dy}}{\mathrm{dx}}$ is got by differentiating equation with respect to ' $x$ ' and substituting location of maximum camber, hence the maximum camber values, and finally get as

$\frac{d y}{d x}=\frac{d z}{d x}=\left\{\begin{array}{lc}0.2-0.5\left(\frac{x}{c}\right), & 0 \leq \frac{x}{c} \leq 0.4 \\ 0.088-0.22\left(\frac{x}{c}\right), & 0.4 \leq \frac{x}{c} \leq 1\end{array}\right.$

And from thin airfoil theory,

$x=\frac{c}{2}\left(1-\cos \theta_{0}\right)$

After substituting $\mathrm{x} / \mathrm{c}$ value in above equation, it become

$$
\frac{d z}{d x}= \begin{cases}0.2-\left(\frac{0.5}{2(1-\cos \theta)}\right), & 0 \leq \theta \leq 1.369 \\ 0.088-\left(\frac{0.22}{2(1-\cos \theta)}\right), & 1.369 \leq \theta \leq 1\end{cases}
$$

After solving the general cambered airfoil equation, the value of zero lift angle for NACA 4412 has been determined as $\alpha_{L=0}=-0.0717 \mathrm{rad}$. Since the theoretical lift slope for the cambered airfoil is $2 \pi$, and the coefficient of lift for NACA 4412 airfoil has been derived from thin airfoil theory as, $C_{l}=2 \pi\left(\alpha-\alpha_{L=0}\right)$, Where, $\alpha=$ Angle of Attack (0, 3, 6, 9, $12,15)$. On substituting the different angles of attack, the coefficient of lift values are obtained and listed in table 2 . The drag coefficient is always associated with the surface area, which can be found using the lift curve slopes for a number of NACA 4 digit series wing sections, plotted against thickness ratio. In the range of thickness ratio from 6 to 10 percent, lift-curve slope is very close to $2 \pi$ per radian. Here lift curve slope decreases with an increase of thickness ratio. By comparing results, inserting a roller proves more efficient.

Table 2: Theoretical results of $C_{L}$ and $C_{D}$

\begin{tabular}{|c|c|c|c|}
\hline \multirow{2}{*}{$\begin{array}{c}\text { Angle of Attack } \\
\text { [ Degree] }\end{array}$} & \multicolumn{3}{|c|}{ NACA 4412 Airfoil with roller } \\
\cline { 2 - 4 } & $\mathrm{C}_{\mathrm{L}}$ & $\mathrm{C}_{\mathrm{D}}$ & $\mathrm{C}_{\mathrm{L}} / \mathrm{C}_{\mathrm{D}}$ \\
\hline 0 & 0.377 & 0.0295 & 12.772 \\
\hline 3 & 0.716 & 0.034 & 20.844 \\
\hline 6 & 1.048 & 0.0364 & 28.733 \\
\hline 9 & 1.337 & 0.0425 & 31.417 \\
\hline 12 & 1.475 & 0.0811 & 18.185 \\
\hline 15 & 1.427 & 0.155 & 9.165 \\
\hline
\end{tabular}

\section{Numerical Simulation}

\subsection{Modelling}

Using the wireframe and surface design parts of CATIA and the various tools and transformation settings have been helped to construct the idealized physical model, which is shown in the figure 1 .

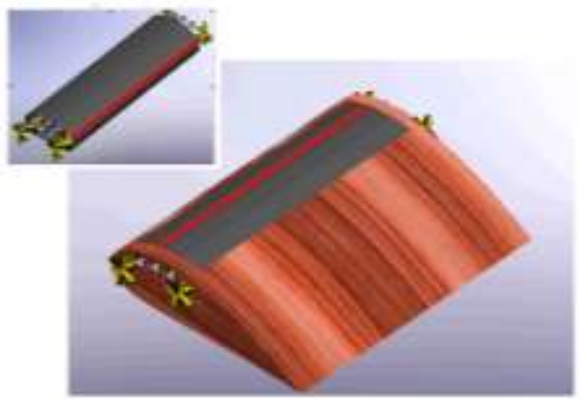

Fig. 1: Idealized physical model 


\subsection{Discretization}

The computational domain extends $12.5 \mathrm{c}$ in front of the leading edge and 20c at the back of the trailing edge. The top and bottom boundary are extended up to $12.5 \mathrm{c}$ from the trailing edge vertically. The generated mesh is a hybrid mesh in a rectangular domain with quadrilateral cells near the airfoil for accurate results and triangular cells further away from the airfoil. The angle of attack is zero for the first case, while for other Angle of Attack (AoA) 3, 6 , 9,12 and 15 degrees are the same procedure for mesh generation is followed. After finishing the progress in ICEM-CFD, the mesh is exported to the Fluent solver. The mesh generated is followed as per industry, which is shown in the figures 2 and 3.

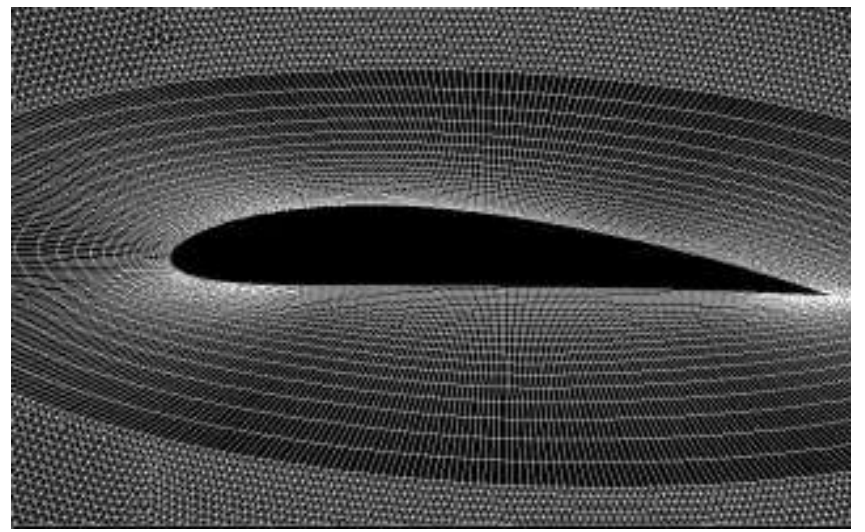

Fig. 2: 2-D Grid system of a NACA 4412 airfoil

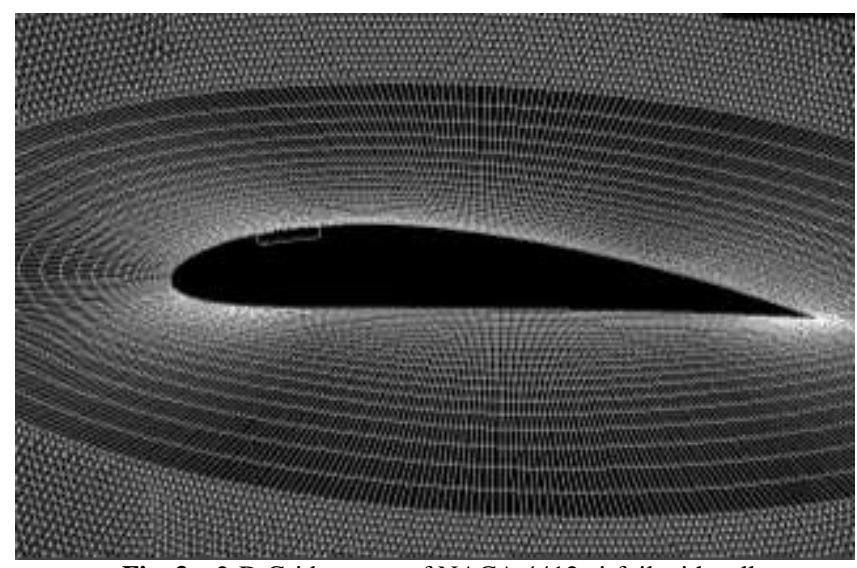

Fig. 3: 2-D Grid system of NACA 4412 airfoil with roller

\subsection{Results and Discussion}

Numerical simulations have been carried out with the help of Computational Fluid Dynamics (CFD) in which k-kl- $\omega$ model is selected as turbulence model. This model is a three-equation eddyviscosity type and it includes transport equations for turbulent kinetic energy laminar kinetic energy and the inverse turbulent time scale [10]. In this model, the compressible flows are described with the inclusion of the compressible treatment of the density. The energy equation will incorporate the coupling between the flow velocity and the static temperature. The code has successfully validated with the help of benchmark solutions. For the wing with roller configuration, a moving wall surface is imposed [11, 12, 13 and 14]. The numerical results presented in this section are a pointer towards design optimization of a dynamic upper surface airfoil for lift enhancement. The figures 4 to 15 show the contours of static pressure and velocity for various Angle of Attack (AoA). The velocity contours of the flow over the airfoil NACA 4412 clearly indicate the boundary layer separation from the leading edge and later forming turbulence at the trailing edge. It also shows that the boundary layer grows with increasing AoA.

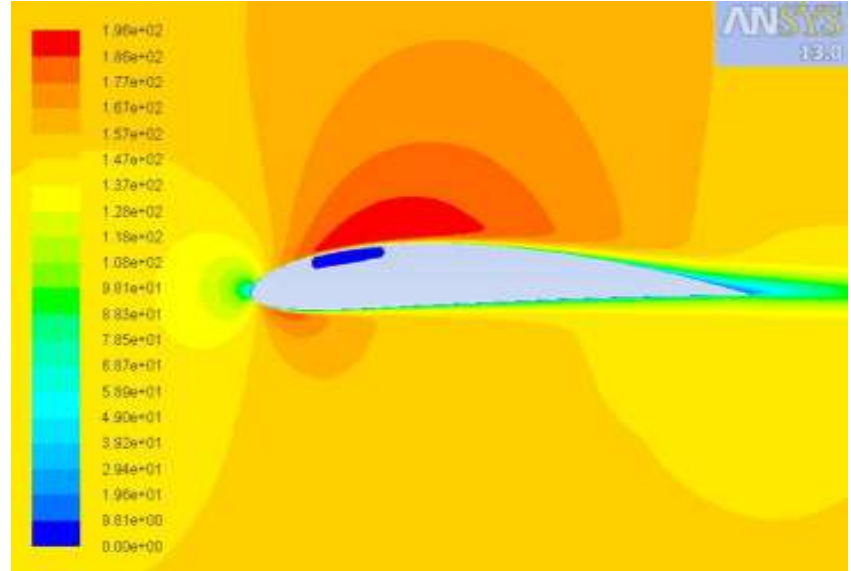

Fig. 4: Velocity variation on airfoil at $0^{0}$ angle of attack

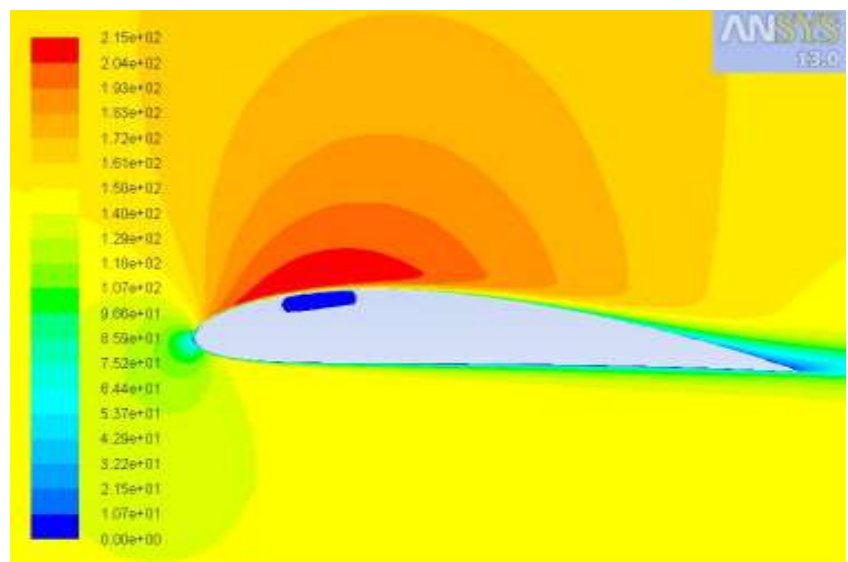

Fig. 5: Velocity variation on airfoil at $3^{0}$ angle of attack

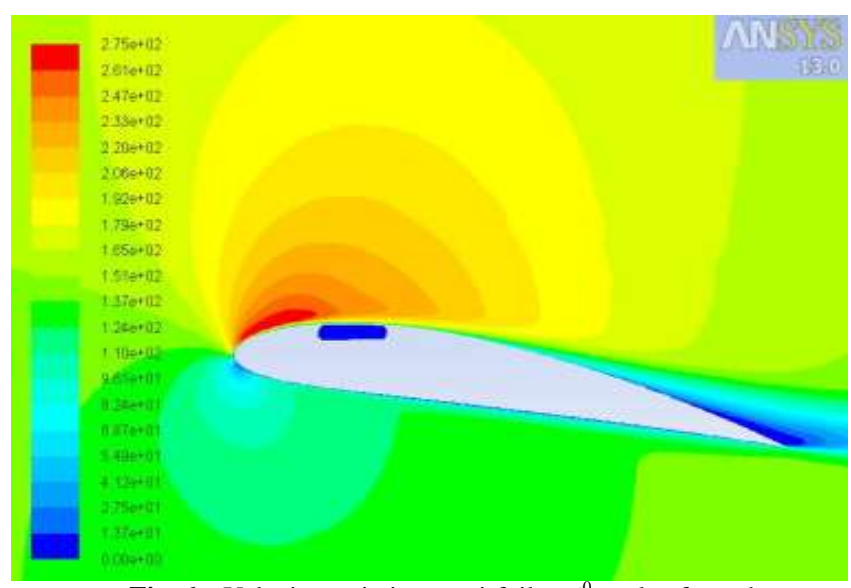

Fig. 6: Velocity variation on airfoil at $6^{0}$ angle of attack

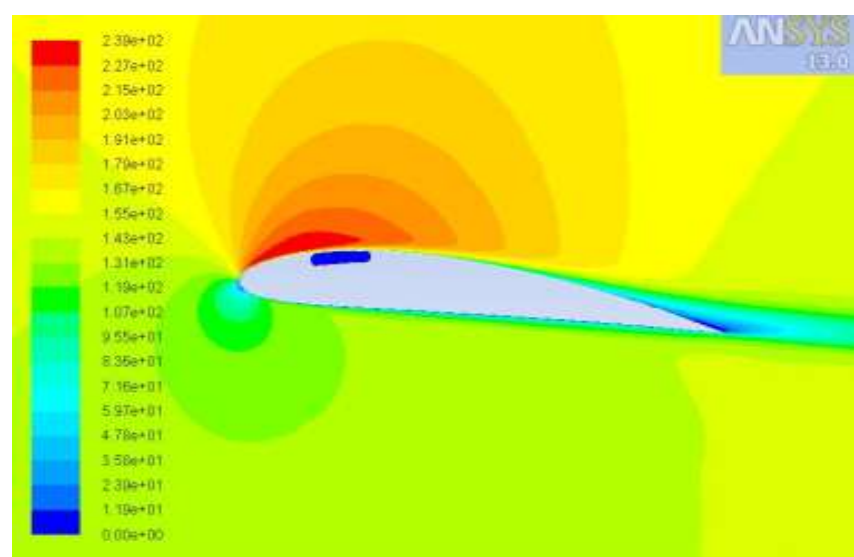

Fig. 7: Velocity variation on airfoil at $9^{0}$ angle of attack 


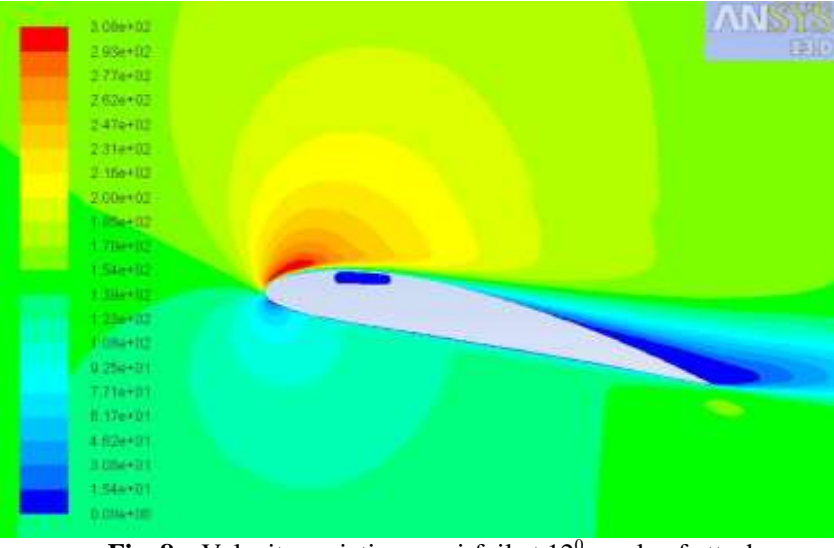

Fig. 8: Velocity variation on airfoil at $12^{0}$ angle of attack

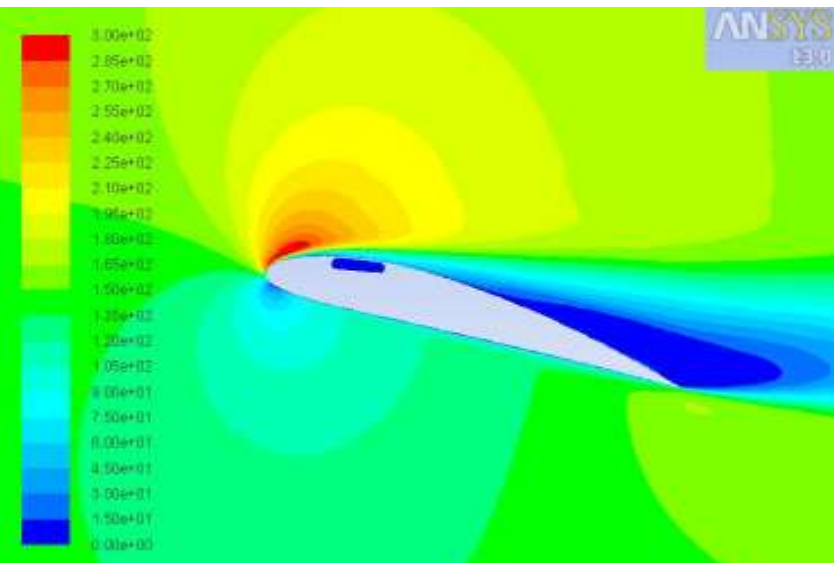

Fig. 9: Velocity variation on airfoil at $15^{0}$ angle of attack

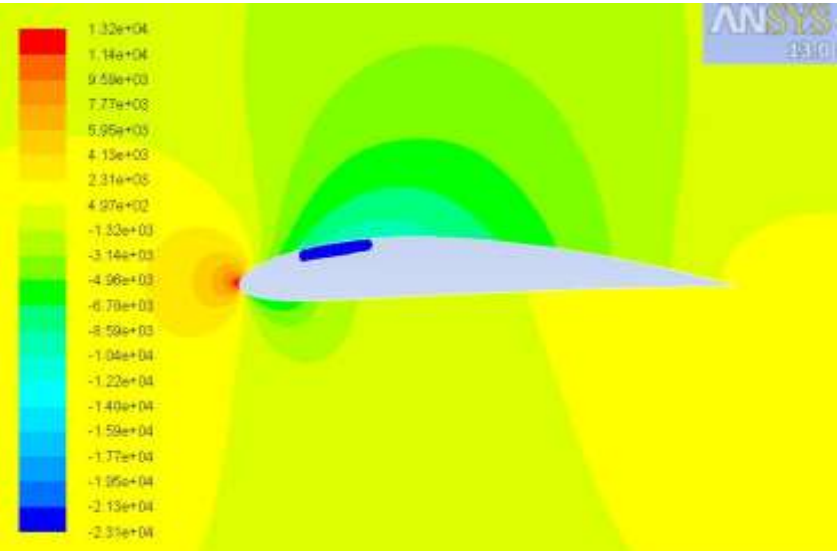

Fig. 10: Pressure variation on airfoil at $0^{0}$ angle of attack

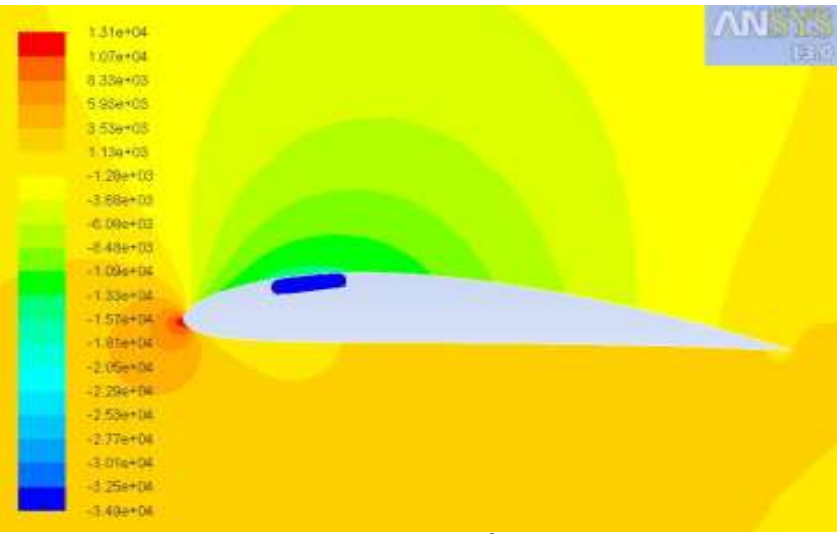

Fig. 11: Pressure variation on airfoil at $3^{0}$ angle of attack

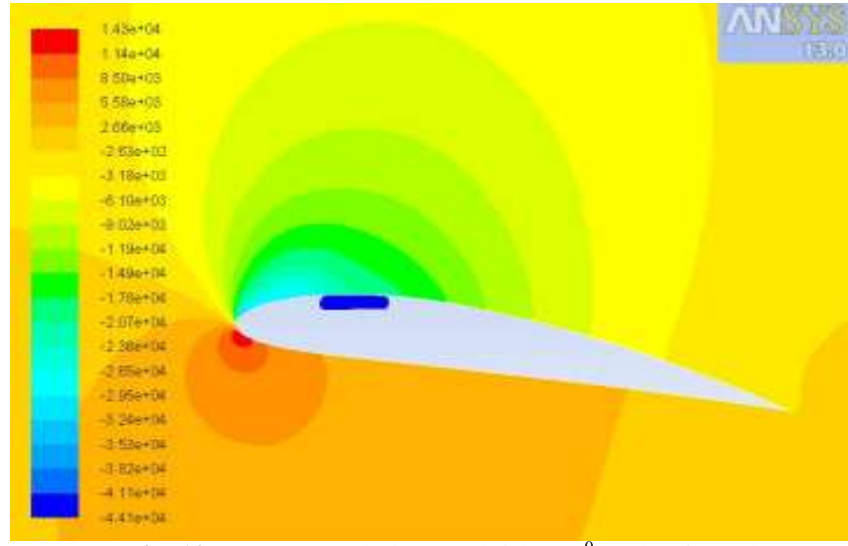

Fig. 12: Pressure variation on airfoil at $6^{0}$ angle of attack

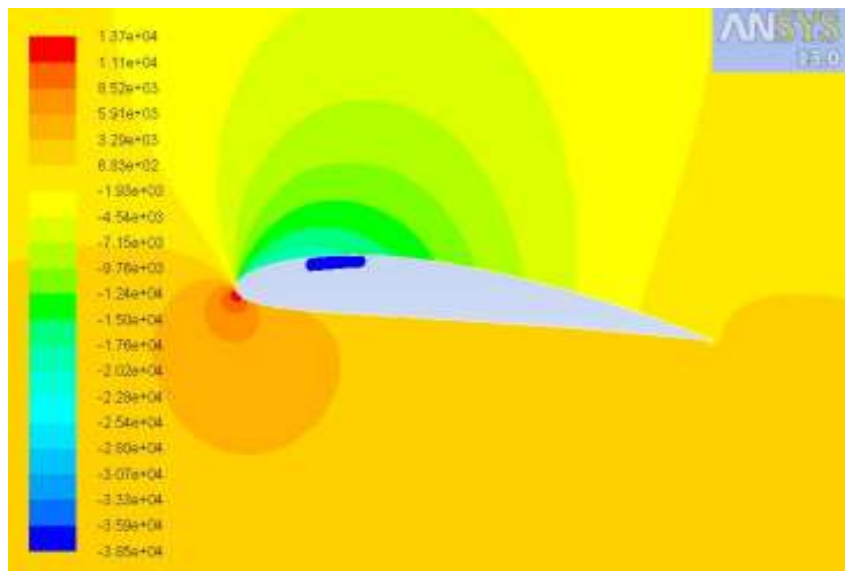

Fig. 13: Pressure variation on airfoil at $9^{0}$ angle of attack

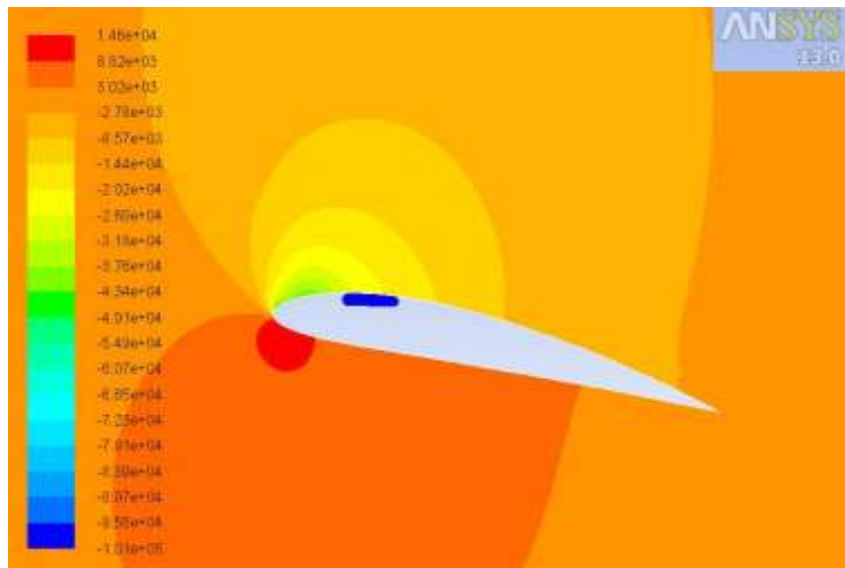

Fig. 14: Pressure variation on airfoil at $12^{0}$ angle of attack

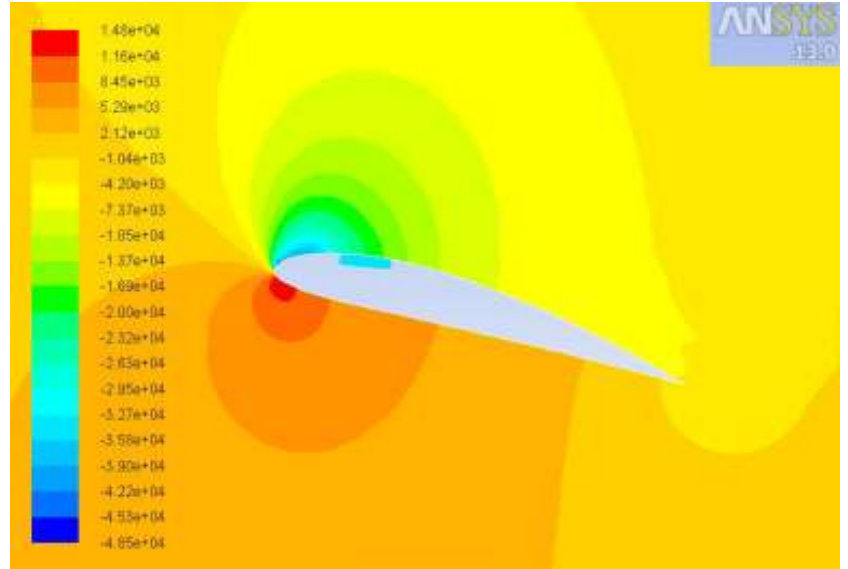

Fig. 15: Pressure variation on airfoil at $15^{0}$ angle of attack 
The values of lift and drag coefficients of NACA 4412 with and without roller are compared. It is seen that the airfoil with roller configuration demonstrates better aerodynamic efficiency than the regular airfoil. Comparative plots of $C_{L}, C_{D}$ and $C_{L} / C_{D}$ for the airfoil with and without roller are shown in the figures 16 to 19 . It is evident that coefficient of drag for the airfoil with the roller is lesser than the airfoil without roller because of the reduction of form drag due to boundary layer separation. Similarly coefficient of lift of airfoil with the roller is greater than the airfoil without roller because of the reduction in the boundary layer over the airfoil with roller surface. From the graphs, it is evident that the results are almost the same for experimental, theoretical and numerical simulation. The results are given in table 1 and 2 .

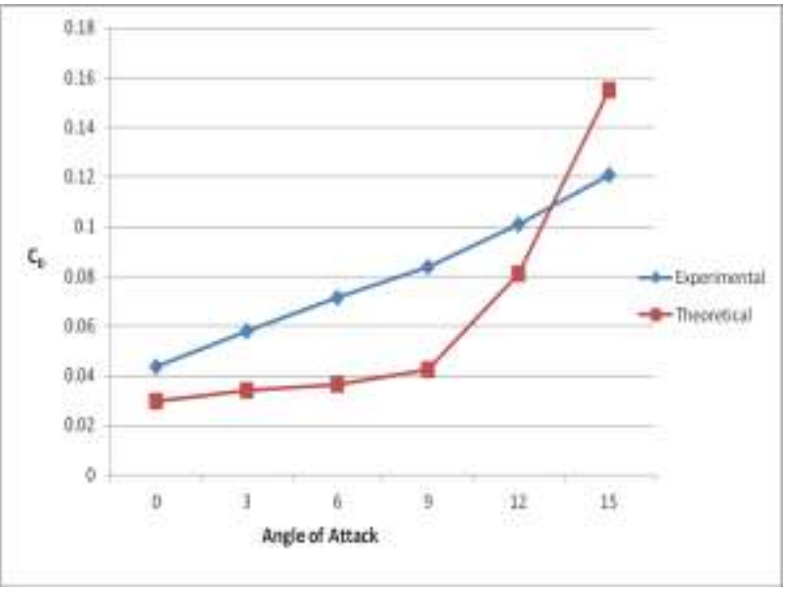

Fig. 16: $C_{D}$ Vs Angle of attack

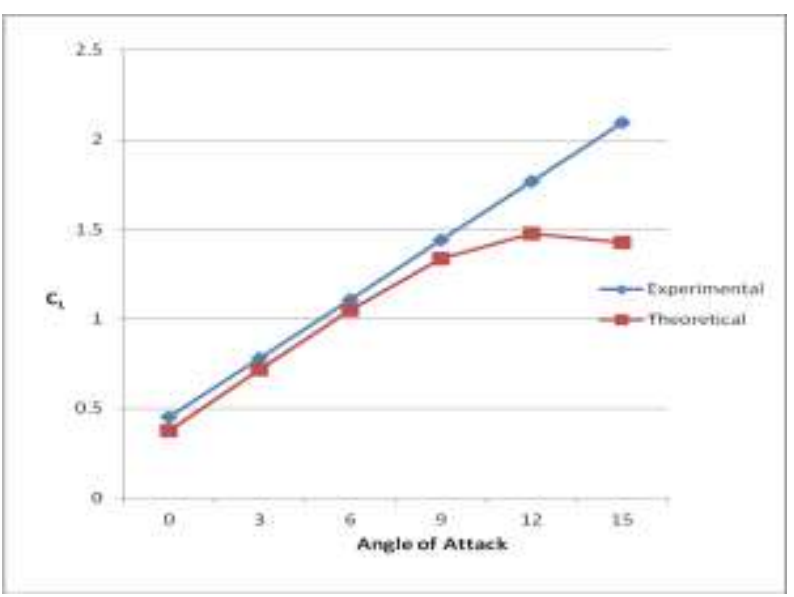

Fig. 17: $C_{L}$ Vs Angle of attack

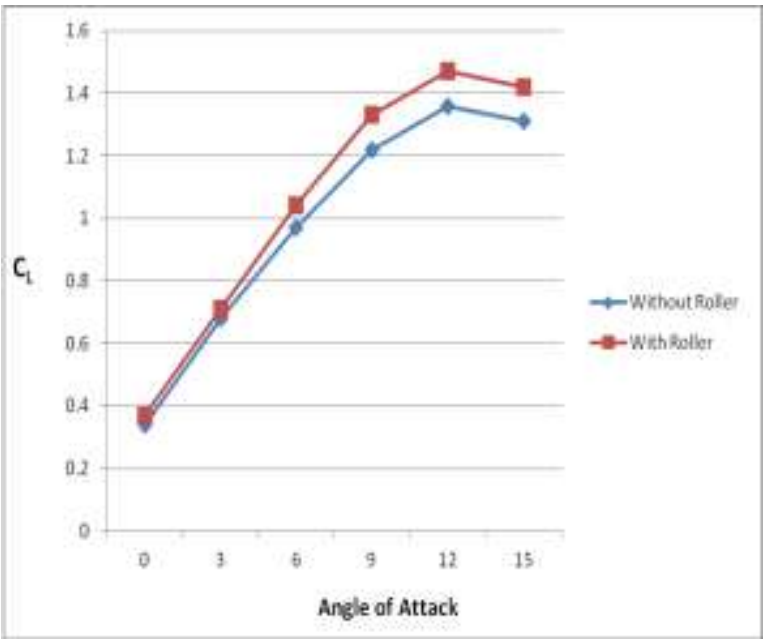

Fig. 18: Comparison of $C_{L}$ for airfoils with and without roller at different AoA

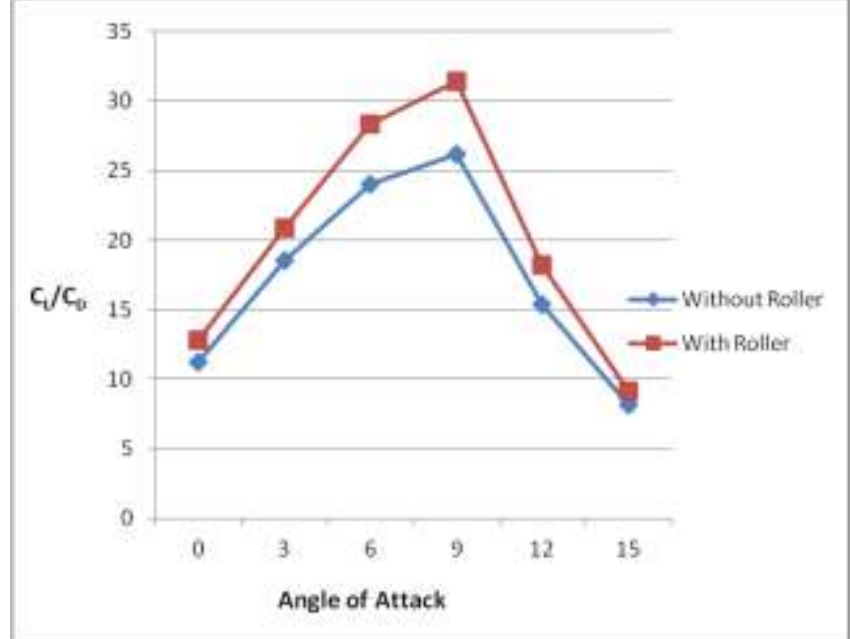

Fig. 19: Comparison of $C_{L} / C_{D}$ for airfoils with and without roller at different AoA

It is evident that coefficient of drag for the airfoil with the roller is lesser than the airfoil without roller because of the reduction of form drag due to boundary layer separation. Similarly, in the comparison of CL for the airfoil with and without airfoil, the coefficient of lift of airfoil with the roller is greater than the airfoil without roller because of the reduction in the boundary layer over the airfoil with roller surface. Further, the numerical simulation results are compared with the experimental results and theoretical results. From the graphs, it is evident that the results are almost the same for experimental, theoretical and numerical simulation. Comparison of with and without the roller plays a major role here, in which the numerical simulation has been used to carry out the results, and thereby the results are plotted and listed in table 3 .

Table 3: Variation of $C_{L} / C_{D}$ with and without roller for the different angle of attack

\begin{tabular}{|c|c|c|c|c|c|c|c|}
\hline \multirow{2}{*}{$\alpha$} & \multicolumn{3}{|c|}{ Without Roller } & \multicolumn{3}{c|}{ With Roller } & $\begin{array}{c}\text { Increase } \\
\text { in } \\
\mathrm{C}_{\mathrm{L}} / \mathrm{C}_{\mathrm{D}} \\
(\%)\end{array}$ \\
\hline & $\mathrm{C}_{\mathrm{L}}$ & $\mathrm{C}_{\mathrm{D}}$ & $\mathrm{C}_{\mathrm{L}} / \mathrm{C}_{\mathrm{D}}$ & $\mathrm{C}_{\mathrm{L}}$ & $\mathrm{C}_{\mathrm{D}}$ & $\mathrm{C}_{\mathrm{L}} / \mathrm{C}_{\mathrm{D}}$ & \\
\hline 0 & 0.34 & 0.030 & 11.22 & 0.37 & 0.02 & 12.77 & 13.83 \\
\hline 3 & 0.68 & 0.036 & 18.50 & 0.71 & 0.03 & 20.84 & 12.61 \\
\hline 6 & 0.97 & 0.040 & 23.99 & 1.04 & 0.03 & 28.33 & 19.76 \\
\hline 9 & 1.22 & 0.046 & 26.15 & 1.33 & 0.04 & 31.41 & 20.11 \\
\hline 12 & 1.36 & 0.088 & 15.42 & 1.47 & 0.08 & 18.18 & 17.90 \\
\hline 15 & 1.31 & 0.161 & 8.172 & 1.42 & 0.15 & 9.165 & 12.15 \\
\hline
\end{tabular}

\section{Conclusion}

Airfoil with roller showed a greater increase in lift and decrease in drag, as compared to conventional NACA 4412 airfoil. Moreover, the roller also reduces the boundary layer thickness by acting as a vortex generator. The laminar to turbulent transition, in the boundary layer, begins with the appearance of downstream moving waves which at first grow slowly and may be described by a linearized equation; however, after reaching certain amplitude, the waves develop strong three-dimensional stature and nonlinearities and, therefore, a rapid transition to turbulence becomes inevitable. It follows that, if effective control is to be achieved, it is essential to have a fast and locally accurate feedback to tame the instabilities before the span-wise differential amplification of the TS waves begins to occur. It may be difficult to obtain the required speed and accuracy with mechanical micro actuators and electromagnetic controlling systems. It is, however, possible with the use of roller surface over the airfoil surface. 


\section{References}

[1] Hermann Schlichting, Klaus Gersten (2017), Boundary Layer Theory, Ninth Edition, New York (USA), and Springer, ISBN-13: 978 3662529171.

[2] John D. Anderson (2005), Ludwig Prandtl's Boundary Layer, Physics Today, American Institute of Physics, pp $42-48$.

[3] Naranjo, A., Cowling, I., Green, J., \&Qin, N (2013), Aerodynamic performance benefits of utilizing camber morphing wings for unmanned air vehicles. The Aeronautical Journal, 117(1189), 315-327. doi:10.1017/S0001924000008010.

[4] Dean Ninian and Sam M. Dakka, (2017), Design, Development and Testing of Shape Shifting Wing Model, Aerospace 2017, 4, 52, pp 1-24, doi:10.3390/aerospace4040052

[5] HenkTennekes, and John L. Lumley (1972), A First Course in Turbulence, MIT Press, ISBN-13: 978-0262200196.

[6] A.D. Polyanin and V.F. Zaitsev (2004), Handbook of Nonlinear Partial Differential Equations, Chapman and Hall / CRC Press, Boca Raton - London, ISBN1-58488-355-3

[7] Chanson, H. (2009), Applied Hydrodynamics: An Introduction to Ideal and Real Fluid Flows". CRC Press, Taylor \& Francis Group, Leiden, the Netherlands, ISBN 978-0-415-49271-3.

[8] O. Sugar Gabor, A. Koreanschi, R. M. Botez (2013), Optimization of an Unmanned Aerial Systems' Wing Using a Flexible Skin Morphing Wing, SAE International Journal of Aerospace, September 2013, vol. 6(1), pp. 115-121.

[9] John Anderson (2016), Fundamentals of Aerodynamics, $6^{\text {th }}$ Edition, ISBN-13: 978-1259129919.

[10] Ira H. Abbott, and A. E. von Doenhoff (1959), Theory of Wing Sections, Dover Publications, ISBN-13: 978-0486605869.

[11] AE Ockfen et al., (2013), Aerodynamic characteristics of NACA 4412 airfoil section with flap in extreme ground effect, Inter J NavArchitOcEngng, 1:1 12, http://dx.doi.org/10.2478/IJNAOE2013-000.

[12] Senthil Kumar M et al., (2017), Conceptual Design and Aerodynamic Drag Investigation of an Automotive Vehicle, 24th National and 2nd International ISHMT-ASTFE Heat and Mass Transfer Conference (IHMTC-2017), BITS Pilani, December 2017.

[13] Senthil Kumar M et al., (2017), Conceptual Design and Comparative Computational Analysis of Secondary inlet of Rotary-wing Aircraft Engine, Journal of Advanced Research in Dynamical and Control Systems, Vol. 9. Sp- 14 / 2017, pp 1189 - 1209.

[14] Manivel R et al., (2018), Pneumafil Casing Blower through Moving Reference Frame (MRF) - A CFD Simulation, 2nd International Conference on Condensed Matter and Applied Physics, AIP Conf. Proc. 1953, 140063-1-140063-5; https://doi.org/10.1063/1.5033238 